\title{
Study on the Pollution Levels of Trace Metals from Modjo Tannery Effluent in the Surrounding River Water and Soil
}

\author{
Amanial Haile Reda \\ Department of Chemistry, College of Natural Sciences, Arbaminch University, Arbaminch, Ethiopia
}

Email address:

amanual.haile@amu.edu.et

\section{To cite this article:}

Amanial Haile Reda. Study on the Pollution Levels of Trace Metals from Modjo Tannery Effluent in the Surrounding River Water and Soil. Science Journal of Analytical Chemistry. Vol. 3, No. 5, 2015, pp. 56-60. doi: 10.11648/j.sjac.20150305.13

\begin{abstract}
This study was conducted to assess the extent of trace metals in Modjo tannery wastewater and their levels of contamination in the vicinity of Modjo river water and agricultural soil. Samples of tannery wastewater, river water and agricultural soils have been analyzed for $\mathrm{Cd}, \mathrm{Cu}, \mathrm{Ni}, \mathrm{Pb}, \mathrm{Zn}$ and $\mathrm{Cr}$ using atomic absorption spectrophotometry (AAS). The result showed that the concentration of $\mathrm{Zn}$ and $\mathrm{Cr}$ metals in Modjo tannery wastewater as well as $\mathrm{Cd}$, $\mathrm{Ni}$ and $\mathrm{Cr}$ in the river water sample were above the standard values of FEPA and WHO. But $\mathrm{Pb}$ was found below the method detection limit for both wastewater and water samples. Results of one - way ANOVA shows that variations for all selected metals in both wastewater and water samples at different sampling points were statistically significant except $\mathrm{Cd}$ in the river water sample. For the agricultural soil sample levels of $\mathrm{Cd}, \mathrm{Ni}, \mathrm{Zn}$ and $\mathrm{Cr}$ were above NEQS standard limit value. The metal contamination factor (CF) also shows that the agricultural soil was highly contaminated $(\mathrm{CF}>6)$ with $\mathrm{Cd}$ and $\mathrm{Cr}$, but moderately contaminated $(1<\mathrm{CF}<3)$ with $\mathrm{Cu}, \mathrm{Ni}, \mathrm{Pb}$ and $\mathrm{Zn}$. Very high contamination factor for $\mathrm{Cr}$ and $\mathrm{Cd}$ was observed in the agricultural soil indicating that both tannery wastewater and river water affects the quality of the soil around the tannery factory.
\end{abstract}

Keywords: Modjo Tannery Wastewater, Modjo River, Trace Metals, Soil Contamination

\section{Introduction}

Advanced industrialization processes have provided comforts to human beings on one hand, and on the other, it has resulted in indiscriminate release of gasses and liquids, which polluted the environment of biological system [1].

Of the various sources of pollutants industrial effluents containing heavy metals pose a threat to the ecosystem. Presence of pollutants in effluent is a common environmental hazard since the toxic metal ions dissolved can ultimately reach the top of the food chain and becomes a risk factor for human beings [2].

According to Akan et al [3], in tannery various chemicals are used during the soaking, tanning and post tanning processing of hides and skins. It has also been reported by UNIDO [4] that only about $20 \%$ of the large number of chemicals used in the tanning process is absorbed by leather, but the rest is released as waste. Tariqu et al [5] also stated that effluents from tanning units are discharged indiscriminately into natural water bodies or open lands, resulting in contamination of the surface and ground waters as well as the soil flora and fauna. Discharges of untreated wastewater to the aquatic environment can result in the accumulation of pollutants. The consequence of this accumulation could result in loss of lively hood, loss of biodiversity and degradation of water quality, which in general affects the ecosystem [6]. Tanneries have been found to discharge not only $\mathrm{Cr}$ which, is an inherent product of the tanning process, significant amounts of $\mathrm{Zn}, \mathrm{Mn}, \mathrm{Cu} \mathrm{Cd}, \mathrm{Pb}$, As, Ni, B, Se, Mo, N and $\mathrm{P}$ have also been observed at the main waste disposal points exceeding the toxic range in soils $[3,7]$. Heavy metals $(\mathrm{Pb}, \mathrm{Cd}, \mathrm{Hg}$ and $\mathrm{As})$ contamination in drinking-water is also seriously threats human health at different levels of diseases [8]. Lead and Copper have no known nutritional and physiological function and they are usually toxic for organisms with a serious cumulative $[9,10]$. The toxicity of $\mathrm{Cr}$ (VI) is also well documented and is considered a hazard to health of man and animals. The various compounds of chromium are found to be both corrosive to flesh and carcinogenic [11,12]. Even though Copper is an essential element to living organism copper together with cadmium is considered as the most toxic heavy metal to soil microorganisms [13]. Similar to copper small amount of nickel is essential for normal growth and reproduction in some species of animals, plant and micro 
organisms [14]. But under various conditions could either activate or inhibit several enzymatic reactions, which are considered to be of crucial importance in humans and other animals, and that interference with these reactions could have severe deleterious effects [15].

Therefore; Modjo tannery is one of the 14 tanneries located along Modjo town, Ethiopia in which its untreated wastewater discharge directly into the Modjo River. The tannery is considered as a source of pollution to the environment and has a strong potential to cause soil and water pollution owing to the discharge of untreated effluent. Most adverse of this tannery effluent is polluting the Modjo river in which the wastewater is discharged to it and the agricultural soil in the vicinity of the tannery. In accordance with the unsafe discharge of the tannery effluent into the nearby environment the present study was formulated to assess the levels of trace metals like $\mathrm{Cd}, \mathrm{Cu}, \mathrm{Ni}, \mathrm{Pb}, \mathrm{Zn}$ and $\mathrm{Cr}$ in the tannery wastewater, river water and agricultural soil.

\section{Materials and Methods}

\section{Study area}

Modjo tanning industry, which is found in Modjo town is located $80 \mathrm{Kms}$ South of Addis Ababa the capital city of Ethiopia and is a medium-sized leather industry with installed capacity of processing 844,000 and 1, 656,000 sheep and goatskins, respectively, per annum [16]. The Plant is sited near the Modjo River and channels its effluents directly to the river course. The volume of wastewater discharged into the Modjo River varies between 3500-5500 cubic meters per day [17]. Apart from its unfortunate use as open waste disposal site the river is also used as a source of drinking and irrigation for the rural population living around the Modjo River.

\subsection{Sampling and Sample Pre-Treatments}

\section{Tannery wastewater and river water sampling}

Tannery wastewater (effluent) samples were collected with 1 L-capacity polyethylene bottles at different distance along the wastewater channel. River water samples from which the tannery wastewater discharged to it were also collected from downstream site of the river at different distance. In a similar way another river water sample was also collected from the upstream site of the river to obtain a background or control sample and is believed free of the Modjo tannery wastewater. All river water samples were collected from the main flow of the stream at 3-5 cm depth. After collection $500 \mathrm{~mL}$ of each of wastewater and water samples were acidified to $\mathrm{pH}<2$ with concentrated nitric acid for metal analysis to prevent the precipitation of metals and finally stored in icebox and transported in to the Hawassa University chemistry department laboratory.

Soil sampling: A composite soil sample was collected from the agricultural area in the vicinity of the tannery from the depth of $0-15 \mathrm{~cm}$. In a similarly way another soil sample was collected from remote areas of the tannery which served as control (background). After the soil samples were transferred to polyethylene plastic bags the samples were stored in icebox until they were transported to the Hawassa University laboratory.

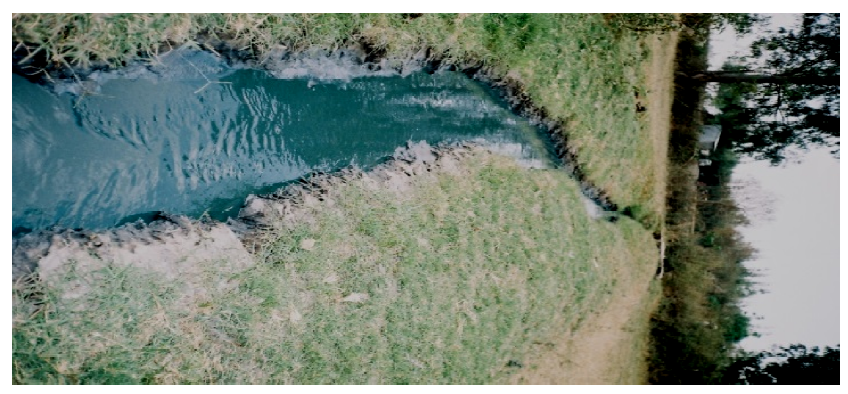

Figure 1. Drain (channel) where Modjo tannery wastewater travels from the source.

\subsection{Digestion of Samples}

Digestion of wastewater and water samples: $100 \mathrm{~mL}$ of each wastewater and water sample was transferred into separate beakers and $2 \mathrm{~mL}$ of concentrated $\mathrm{HNO}_{3}$ and $5 \mathrm{~mL}$ of concentrated $\mathrm{HCl}$ were added to each beaker and covered with a ribbed watch glass. The beaker was heated on a hot plate at 90 to $95^{\circ} \mathrm{C}$ until the volume has been reduced to 15 $20 \mathrm{~mL}$. After cooling the beaker wall and watch glass were washed with distilled water and the sample was filtered to remove any insoluble materials that could clog the atomizer. Finally the volume was adjusted to $100 \mathrm{~mL}$ with reagent water [18] and measurement was done using AAS.

Digestion of soil sample: The soil sample was air-dried, homogenized and ground into fine powder using pestle and mortar and passed through $1 \mathrm{~mm}$ sieve. Finally, $1.0 \mathrm{~g}$ of soil sample was transferred to $250 \mathrm{~mL}$ Griffin beaker and $10 \mathrm{~mL}$ of $1: 1 \mathrm{HNO}_{3}$ was added and heated to $95{ }^{\circ} \mathrm{C}$ and refluxed for 15 minutes. After cooling, $5 \mathrm{~mL}$ concentrated $\mathrm{HNO}_{3}$ was added and then heated to $95{ }^{\circ} \mathrm{C}$, and refluxed for 30 minutes until no brown fumes was given off by the sample. The mixture was refluxed again to approximately $5 \mathrm{~mL}$ at $95{ }^{0} \mathrm{C}$ without boiling for two hours. After cooling, $2 \mathrm{~mL}$ of water and $3 \mathrm{~mL}$ of $30 \% \quad \mathrm{H}_{2} \mathrm{O}_{2}$ were added heated until effervescence subsides. Further, $1-\mathrm{mL}$ of $30 \% \mathrm{H}_{2} \mathrm{O}_{2}$ was added until the general sample appearance was unchanged and digested until the volume has been reduced to approximately $5 \mathrm{~mL}$ without boiling for two hours. Finally, $10 \mathrm{~mL}$ concentrated $\mathrm{HCl}$ was added and refluxed at $95{ }^{\circ} \mathrm{C}$ for 15 minutes and then the sample was filtered and diluted to $100 \mathrm{~mL}$ volumetric flask [19]. Measurement for the trace metal was done using AAS.

Statistical analysis: The significance of variation within sample and between samples has been studied using oneway analysis of variance (ANOVA) for effluent (wastewater) and water samples. The least significant difference (LSD) method was applied to test the mean differences at the 5\% level of significance. Two sided t-test was also used for soil samples. All statistical data analysis was carried out using stastical package for social studies (SPSS) software version 16.0 . 


\section{Results and Discussion}

\subsection{Levels of Trace Metals Along the Wastewater Channel}

Table 1. Average concentration (mean $\pm S D, n=3, m g L^{-1}$ ) of metals in Modjo tannery wastewater channel.

\begin{tabular}{llll}
\hline \multirow{2}{*}{ Metal } & Sampling sites & & \\
\cline { 2 - 4 } & E1 & E2 & E3 \\
\cline { 2 - 4 } & Mean \pm SD & Mean \pm SD & Mean \pm SD \\
\hline $\mathrm{Cd}$ & $0.081 \pm 0.003$ & $0.043 \pm 0.002$ & $0.040 \pm 0.002$ \\
$\mathrm{Cu}$ & $0.31 \pm 0.02$ & $0.22 \pm 0.01$ & $0.17 \pm 0.01$ \\
$\mathrm{Ni}$ & $0.85 \pm 0.06$ & $0.75 \pm 0.04$ & $0.64 \pm 0.07$ \\
$\mathrm{~Pb}$ & $\mathrm{ND}$ & $\mathrm{ND}$ & $\mathrm{ND}$ \\
$\mathrm{Zn}$ & $2.81 \pm 0.001$ & $2.30 \pm 0.07$ & $1.99 \pm 0.24$ \\
$\mathrm{Cr}$ & $282.59 \pm 20.42$ & $174.64 \pm 25.55$ & $132.03 \pm 13.22$ \\
\hline
\end{tabular}

ND: Concentration of the tested metal below the method detection limit

The concentrations of the metals studied along the wastewater channel showed a decrease in concentration from the point source (E1) up to $800 \mathrm{~m}$ (E3), in the order of $\mathrm{E} 1>\mathrm{E} 2>\mathrm{E} 3$ (table 1) and this might be due to adsorption of the metal within the wall of discharged channel soil. Analysis of variance (ANOVA) indicated that variation among points were statistically significant $(\mathrm{p}<0.05)$ except $\mathrm{Pb}$. But the level of $\mathrm{Pb}$ was below the method detection limit $\left(0.05 \mathrm{mgL}^{-}\right.$ $\left.{ }^{1}\right)$; hence no appreciable amount of $\mathrm{Pb}$ was detected at all sampling points of the wastewater channel. The mean concentrations of $\mathrm{Zn}$ and $\mathrm{Cr}$ at all sampling points along the wastewater channel were higher than the standard limits for industrial effluents to be discharged to water bodies set by WHO [20] and FEPA [16] which is $1 \mathrm{mgL}^{-1}$. Especially the concentration $\mathrm{Cr}$ was found elevated by about an average of 196 times the standard value of WHO. The high value of $\mathrm{Cr}$ mentioned above is due to the fact that $\mathrm{Cr}$ is a compound of tannery effluent emanating from the use of chromium salt. Continuous discharge of chromium in low concentration has been reported to be toxic to aquatic life and has been shown to disrupt the aquatic food chain [2].

\subsection{Levels of Trace Metals in Water Samples of River}

Table 2. Average concentration (mean $\pm S D, n=3, m g L^{-1}$ ) of selected metals in water sample.

\begin{tabular}{llll}
\hline \multirow{2}{*}{ Metal } & Sampling sites & & \\
\cline { 2 - 4 } & W1 & W2 & Wup (control) \\
\cline { 2 - 4 } & Mean \pm SD & Mean \pm SD & Mean \pm SD \\
\hline $\mathrm{Cd}$ & $0.023 \pm 0.002$ & $0.021 \pm 0.002$ & $0.011 \pm 0.001$ \\
$\mathrm{Cu}$ & $0.12 \pm 0.002$ & $0.038 \pm 0.003$ & $0.030 \pm 0.003$ \\
$\mathrm{Ni}$ & $0.24 \pm 0.002$ & $0.064 \pm 0.003$ & $0.04 \pm 0.001$ \\
$\mathrm{~Pb}$ & $\mathrm{ND}$ & $\mathrm{ND}$ & $\mathrm{ND}$ \\
$\mathrm{Zn}$ & $1.22 \pm 0.002$ & $0.49 \pm 0.01$ & $0.20 \pm 0.003$ \\
$\mathrm{Cr}$ & $72.14 \pm 3.8$ & $9.99 \pm 1.89$ & $1.2 \pm 0.09$ \\
\hline
\end{tabular}

ND: Concentration of the tested metal below the method detection limit.

The average concentration of $\mathrm{Cd}, \mathrm{Cu}, \mathrm{Ni}, \mathrm{Zn}$ and $\mathrm{Cr}$ except $\mathrm{Pb}$ shows a decrease in their concentration from $\mathrm{W} 1$ to $\mathrm{W} 2$ in the downstream site of the river (table 2). This indicated that the distribution of metals becomes less as the distance increases downstream and thus decrease in concentration might be due to dilution and adsorption of the metal by sediments and organic matters present in the river water. Akan et al [3] also stated that metal adsorbs strongly to sediments and organic matters. One way ANOVA also showed that variations among the different sampling points were statistically significant $(\mathrm{p}<0.05)$ for all metals except $\mathrm{Cd}$. But the concentration of $\mathrm{Pb}$ was below the method detection limit at all the sampling points.

The levels of $\mathrm{Cd}, \mathrm{Ni}$ and $\mathrm{Cr}$ in both sampling sites of the river $\mathrm{W} 1$ and $\mathrm{W} 2$ were higher than the guide line value of water quality set by WHO [21] which is $0.003 \mathrm{mgL}^{-1}, 0.02$ $\mathrm{mgL}^{-1}$ and $0.05 \mathrm{mgL}^{-1}$ respectively. High concentration of these metals in W1 and W2 were also recorded as compared to values obtained in the Wup which is up steam site of the river used as control (table 2). This indicated that the high concentrations of these metals in the downstream site of the river are due to the direct discharge of tannery wastewater to the river water and the river is polluted by these trace metals. Whereas the mean concentrations of $\mathrm{Cu}$ and $\mathrm{Zn}$ in the downstream site of the river $\mathrm{W} 1$ and $\mathrm{W} 2$ were within the guide line values of water quality set by WHO which is 1.0 $\mathrm{mgL}^{-1}$ and $5.0 \mathrm{mgL}^{-1}$ respectively. The concentrations of these metals in the downstream site of the river W1 and W2 were also above the values obtained from the upstream site of the river Wup used as control (Table 2). This indicated that an increased in the levels of these metals in the downstream site of the river is due to the discharged tannery effluent. Even though the current concentrations of these metals were within the standard values of WHO but till there is an increase in concentration of these metals and thus might also increase the accumulation of these metals on the sediments and organic matters present in the river.

\subsection{Levels of Trace Metals in Soil Samples}

The average concentrations of $\mathrm{Cd}, \mathrm{Ni}, \mathrm{Zn}$ and $\mathrm{Cr}$ in the agricultural soil sample Ss were 3.14, 31.8, 241.6 and $2017.24 \mathrm{mgkg}^{-1}$ respectively (table 3 ). All these values were above the values given in the National Environmental Quality Standards (NEQS) of soil which is 0.5, 20, 60 and 20 $\mathrm{mgkg}^{-1}$ respectively. In addition to this the levels of these metals in the agricultural soil in the vicinity of the tannery were also above the value obtained from the control soil sample $\mathrm{Sb}$ which is collected from the remote areas of the tannery (table 2). t-test also showed that mean concentrations of $\mathrm{Cd}, \mathrm{Ni}, \mathrm{Zn}$ and $\mathrm{Cr}$ in both $\mathrm{Ss}$ and $\mathrm{Sb}$ were statistically significant $(p<0.05)$. Thus result indicated that there is a pollution and accumulation of these trace metals in the agricultural soil as a result of the river water used for irrigation purpose. Whereas the average concentrations of $\mathrm{Cu}$ and $\mathrm{Pb}$ in the agricultural soil Ss were 22.89 and $9.56 \mathrm{mgkg}^{-1}$ and both values were within the standard values given by NEQS which is $100 \mathrm{mgkg}^{-1}$ and $25 \mathrm{mgkg}^{-1}$ respectively. But the concentrations of both $\mathrm{Cu}$ and $\mathrm{Pb}$ in Ss were higher as compared to the values obtained from the $\mathrm{Sb}$ which is used as control. t-test also showed that mean concentrations of $\mathrm{Cu}$ and $\mathrm{Pb}$ in $\mathrm{Ss}$ and $\mathrm{Sb}$ were statistically significant $(\mathrm{p}<0.05)$. Thus might be due to the gradual accumulation of these trace metals as a result of the river water used for irrigation. 
Soil contamination factor (CF) was also calculated using equation given by [22]. Where $\mathrm{CF}<1$ refers to low contamination; $1 \leq \mathrm{CF}<3$ means moderate contamination; 3 $\leq \mathrm{CF} \leq 6$ indicates considerable contamination and $\mathrm{CF}>6$ indicates very high contamination. The $\mathrm{CF}$ values of $\mathrm{Cd}$ and Cr were 6.41 and 364.12 and this shows that the agricultural soil is very high contaminated with $\mathrm{Cd}$ and $\mathrm{Cr}$ but moderately contaminated with $\mathrm{Cu}, \mathrm{Ni}, \mathrm{Pb}$ and $\mathrm{Zn}$ with their $\mathrm{CF}$ values of $1.48,2.12,1.35$ and 1.39 respectively.

Table 3. Average concentrations (mean $\pm S D, n=3, m g K g^{-1}$ ) of selected metals in soil samples.

\begin{tabular}{lll}
\hline \multirow{2}{*}{ Metal } & \multicolumn{2}{l}{ Sampling sites } \\
\cline { 2 - 3 } & Ss & Sb (control) \\
\cline { 2 - 3 } & Mean \pm SD & Mean \pm SD \\
\hline $\mathrm{Cd}$ & $3.14 \pm 0.06$ & $0.49 \pm 0.01$ \\
$\mathrm{Cu}$ & $22.89 \pm 0.39$ & $15.51 \pm 0.27$ \\
$\mathrm{Ni}$ & $31.8 \pm 1.1$ & $15.03 \pm 0.71$ \\
$\mathrm{~Pb}$ & $9.56 \pm 0.43$ & $7.09 \pm 0.19$ \\
$\mathrm{Zn}$ & $241.6 \pm 1.1$ & $173.88 \pm 1.37$ \\
$\mathrm{Cr}$ & $2017.24 \pm 2.01$ & $5.54 \pm 1.03$ \\
\hline
\end{tabular}

\section{Conclusion}

Thus study showed that concentrations of $\mathrm{Cd}, \mathrm{Cu} \mathrm{Ni}, \mathrm{Zn}$ and $\mathrm{Cr}$ decreased with distance from point source in both the wastewater channel and river water. Analysis of variance also showed that variations among sampling points were statistically significant except $\mathrm{Cd}$ in the river water sample. The levels of $\mathrm{Zn}$ and $\mathrm{Cr}$ along the tannery wastewater channel were above the international standard values set by FEPA and WHO for tannery effluents to be discharged into water bodies. In the river water concentrations of $\mathrm{Cd}, \mathrm{Ni}$ and $\mathrm{Cr}$ were above the WHO guide line of water quality. In downstream site of the river where the tannery wastewater travels through the levels of $\mathrm{Cd}, \mathrm{Cu} \mathrm{Ni}, \mathrm{Zn}$ and $\mathrm{Cr}$ were also higher as compared to the values obtained in the upstream site of the river which is used as control and is expected free of the Modjo tannery wastewater. In the agricultural soil the levels of $\mathrm{Cd}, \mathrm{Ni}, \mathrm{Zn}$ and $\mathrm{Cr}$ were much greater compared to background (control) soil sample and international standard values set by NEQS of soil quality. This indicated that the soil around the tannery is polluted with $\mathrm{Cd}, \mathrm{Ni}, \mathrm{Zn}$ and $\mathrm{Cr}$ from the tannery wastewater and river water. In general the tannery wastewater has a large contribution for the pollution of the river water and agricultural soil. Consequently, over time, excessive metal accumulation in soil and water might affect the quality of the natural resources around the tannery.

\section{Recommendation}

In general, the release of untreated wastewater from Modjo tannery influenced the receiving water body and surrounding soil. Therefore, it is recommended that the treatment of wastewater is not only desirable but also necessary to correct wastewater characteristics so that its use or final disposal of the treated effluents can take place without causing an adverse impact on the receiving water body and surrounding soil. In addition to this further work on the impact of tannery wastewater on sediments of the river and in the surrounding growing crop and cultivated vegetation is necessary to assess the impact of tannery wastewater in the surrounding environments.

\section{References}

[1] Lone, M. I., Saleem, S., Mahmood, T., Saifullah, K. and Hussain, G. (2003). Heavy metal contents of vegetable irrigated by sewage/tube well water. International Journal of Agriculture \& Biology. 05:533 - 535.

[2] Baby, S. P. (2010). Effect of tannery effluent on water and soil profile, plant growth and human health, $\mathrm{PhD}$ thesis. Avinashilingam Deemed University for Women, Coimbatore 43. 1-7.

[3] Akan, J. C., Abdulrahman, F. I., Ayodele, J. T. and Ogugbuaja, V.G. (2009). Impact of tannery and textile effluent on the chemical characteristics of Challawa River, Kano state, Nigeria. Electronic Journal of Environmental, Agricultural and Food chemistry. 8:1008-1032.

[4] UNIDO. (2005). United Nations industrial development organization, cost of tanned waste treatment, 15th session of the leather and leather products industry panel, Leon, Mexico.

[5] Tariq, S.R., Shah, M. H., Shaheen, N., Khalique, A., Manzoor, S. and Jaffar, M. (2006). Multivariate analysis of trace metal levels in tannery effluents in relation to soil and water: A case study from Peshawar, Pakistan. Journal of Environmental Management. 79:20-29

[6] Babatunde, A. O., Zhao, Y. Q., O'Neill, M., O'Sullivan, B. (2008). Constructed wetlands for environmental pollution control: A review of developments, research and practice in Ireland. Environment International. 34:116-126

[7] Ogbonna, J. O., Lawal, F. A., Owoeye, L. D. and Udeh, M. U. (1998). Chemical characteristics and fertilizing value of primary sludge from tannery effluent treatment plant, paper presented at the $16^{\text {th }}$ annual national conference of the Nigerian institute of science and technology at University of Ibadan.24-27th November, 1998.

[8] Surya Dev, P.Y., Kalpana, M., Narendra, K. C., Parashuram, M. (2015). Assessing Physico-Chemical Parameters of Potable Water in Dhankuta Municipality of Nepal. Science Journal of Analytical Chemistry.3 (2):17-21.

[9] Ramessur, R. T., Ramjeawon, T. (2002). Determination of lead, chromium and zinc in sediments from an urbanized River in Mauritius. Environment International. 28: 315-324.

[10] Willson, A. L. (1979). Trace metals in water: Philosophical transactions of the royal society of London. Journal of Biological Science. 288:25-39.

[11] Khasim, D. I., Nanda, N. V. and Hussain, R. C. (1989). Environmental contamination of chromium in agricultural and animal products near chromate industry. Bulletin Environmental Contaminated Toxicology. 43:742-746.

[12] Teklit, G. A. (2015). Plant, soil and water pollution due to tannery effluent a case study from Sheb Tannery, P.L.C,Wukro Tigray, Ethiopia. Science Journal of Analytical Chemistry. $3(5): 47-51$. 
[13] Alloway, B. J. (1994). Toxic metals in soil-plant systems. Chichester, UK: John Wiley and sons. 3-26.

[14] Mertz, W. (1981).The essential trace elements. Science.213:1332-1338

[15] Vallee, B. L. (1951). The function trace elements in biology. The Scientific Monthly. 72:368-376

[16] FEPA. (1991). Guidelines to standards for environmental pollution control in Nigeria, Lagos, Nigeria.10-20

[17] Tesfaye, M. (2006). Biological nitrogen removal from tannery wastewater using alkaliphilic sludge. M.Sc thesis. Addis Ababa University. Addis Ababa. 2-18
[18] Method 3005A. (1992). Acid digestion of waters for total recoverable or dissolved metals

[19] Method 3005A. (1992). Acid digestion of waters for total recoverable or dissolved metals for analysis by FAAS or ICP spectroscopy

[20] WHO. (1998). Standards for effluent discharges, Geneva

[21] WHO. (1984). Guidelines for drinking water quality, Geneva.

[22] Mmolawa1, K. B., Likuku, A.S. and Gaboutloeloe, G.K. (2011). Assessment of heavy metal pollution in soils along major roadside areas in Botswana. African Journal of Environmental Science and Technology. 5:186-196. 